\title{
Structural and electrical properties of new core-shell silver poly(m-toluidine-co-2-bromoaniline) nanocomposites
}

\author{
A. Mahudeswaran ${ }^{1}$, A. JeEva $^{2}$, J. ChandraseKaran $^{3}$, P.S. ViJayanand $^{2, *}$ \\ ${ }^{1}$ Department of Physics, Bannari Amman Institute of Technology, Sathyamangalam, Erode, Tamil Nadu, 638 401, India \\ ${ }^{2}$ Department of Chemistry, Bannari Amman Institute of Technology, Sathyamangalam, Erode, Tamil Nadu, 638 401, India \\ ${ }^{3}$ Department of Physics, Ramakrishna Mission Vidyalaya College of Arts and Science, Coimbatore, Tamil Nadu, 641020 , \\ India
}

\begin{abstract}
In this article, we report the synthesis and characterization of silver dispersed poly(m-toluidine-co-2-bromoaniline) copolymer synthesized by chemical oxidative polymerization method. The synthesized copolymer composites were subjected to different analytical characterization methods, such as FT-IR, UV, XRD, SEM, photoluminescence and electrical conductivity studies. All the polymer samples are found to be soluble in common organic solvents. UV absorption spectra show a red shift when silver nanoparticles are dispersed in the copolymer. The characteristic peaks observed in FT-IR spectra confirm the formation of the copolymer. XRD pattern reveals the crystalline nature of the copolymer composites and sharp peaks in the spectra confirm the presence of silver particles. The silver nanoparticles change the surface morphology in the form of perfect encapsulation. The electrical conductivity of the polymer composites is found to vary from $10^{-4} \mathrm{~S} / \mathrm{cm}$ to $10^{-6} \mathrm{~S} / \mathrm{cm}$. PL study reveals the charge transfer between the copolymer and the silver particles.
\end{abstract}

Keywords: m-toluidine; o-bromoaniline; copolymer; silver nanoparticles; electrical conductivity; photoluminescence quenching

\section{Introduction}

Research works based on conjugated polymers and their composites have attracted many researchers due to unique electrical properties of these compounds [1,2]. Nowadays, miniature sized conducting polymers are much preferred because of their interesting properties used in nanodevices [3]. The conjugated polymers are able to change their electrical and optical properties depending on the external impulses like the presence of oxidants, reductants, change in temperature, humidity and acidity [4-6]. Polymer with semiinterpenetrating network structure can be used as electrolyte separator in lithium ion batteries [7]. Chuanyu et al. [8, 9] studied the factors that influence the preparation of conducting polyaniline and synthesized polyaniline nanotubes by template method under UV radiation. Polyaniline nanostructures have been synthesized and applied to develop

*E-mail: vijayps6@yahoo.co.in ammonia sensor [10]. The fluorine doped polymers can be used to improve the efficiency and stability of perovsksite solar cells and polymer complexes for solar fuels [11-13].

The properties and application perspectives of conjugated polymers can be further improved by synthesizing the polymer composites with dispersion of metal nanoparticles (hybrid materials). This is fascinating research work in the development of flexible semiconductors. Graphene based polyaniline composites found applications in supercapacitors, sensing platforms, fuel cells, solar cells, electrochromic devices, lithium ion batteries etc. [14]. The electrical properties of conducting polymer hybrid nanocomposites depend on the mutual proportions of the metal nanoparticles embedded into the polymer matrix. These nanostructures possess excellent electrical properties to fabricate different devices such as sensors and capacitors because of excellent catalytic activities, optical and electrical properties and unique morphology in controlled conditions [15]. Many noble metals, such 
as gold, platinum, cadmium etc., have been incorporated into the conjugated polymers [16-18]. Among them, silver has received much attention due to its high conductivity value, as high as $5.6 \times 10^{5} \mathrm{~S} / \mathrm{cm}$ at room temperature and the fact that it is relatively cheaper than any other metal.

Gupta et al. [19] reported that incorporation of silver nanoparticles into the polyaniline matrix through chemical oxidative polymerization is a simple way to enhance the optical and electrical properties of the conducting polymers. Biswas et al. [20] has reported about the synthesis of polyaniline-silver nanocomposites in two different ways: one stage and two stage reactions. The one step process has been more effective than the other methods because of higher mono-dispersity of silver nanoparticles within the polyaniline matrix. Bober et al. [21-23] estimated the content of silver in PANI nanocomposite but the expected conductivity was not achieved. In presence of methane sulfonic acid, a high yield and good conducting nanocomposites were synthesized but the heterogeneity of the samples was rather poor. In cooperation with our research group, Vivekanandan et al. [24, 25] reported about incorporation of silver nanoparticles into the polyaniline based copolymers of aniline and $\mathrm{m}$-chloroaniline.

In the literature, however, no report has been published on silver dispersion in m-toluidine and o-bromoaniline copolymers. Hence, in this work we report the synthesis and characterization of a novel poly(m-toluidine-co-2-bromoaniline) copolymer and silver dispersion in the copolymer matrix. The composites were subjected to various analytical characterizations such as UV-Vis, FT-IR, $\mathrm{XRD}$, surface morphology, electrical conductivity and photoluminescence studies.

\section{Materials and methods}

The following chemicals were used in the experiments: o-toluidine (Ranken, India) purified by vacuum distillation method, m-bromoaniline (Hi Media (India), ammonium peroxidisulfate and $\mathrm{HCl}$ (E-Merck India), DBSA (Hi Media), silver nitrate (Merck), and $\mathrm{NaOH}$ (Hi Media). The solvents NMP, DMSO and DMF were purchased from Hi
Media and used as delivered. Double distilled water was used for the synthesis.

\subsection{Synthesis of copolymer}

The synthesis procedure for poly(m-toluidineco-2-bromoanilne) copolymer was as follows: $0.05 \mathrm{M}$ of $\mathrm{m}$-toluidine and $0.05 \mathrm{M}$ of o-bromoaniline were dissolved in $100 \mathrm{~mL}$ of $1 \mathrm{M}$ $\mathrm{HCl}$ solution and stirred well. $0.1 \mathrm{M}$ of ammonium persulfate solution was added dropwise into the mixture. The temperature of the reaction was maintained between $0{ }^{\circ} \mathrm{C}$ and $5{ }^{\circ} \mathrm{C}$ and the mixture was stirred for $24 \mathrm{~h}$. A dark green colored precipitate formed and it was washed with distilled water and acetone. Then all the samples were dried in a vacuum oven at $40{ }^{\circ} \mathrm{C}$ for $12 \mathrm{~h}$. The obtained copolymer product was composed of monomers in 3:3 molar ratio. Similar procedure was carried out to synthesize $3: 2$ and $3: 1$ ratio of m-toluidine and o-bromoaniline copolymers.

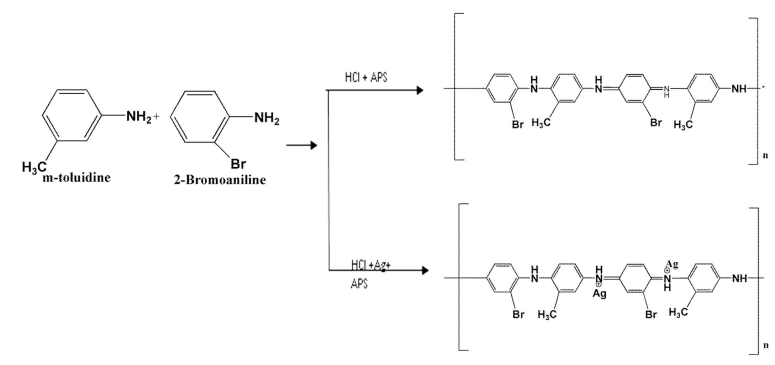

Fig. 1. Scheme of the copolymer.

\subsection{Synthesis of silver nanoparticles}

$3.26 \mathrm{~g}(0.1 \mathrm{M})$ of dodecylbenzene sulfonic acid (DBSA) was added into $90 \mathrm{~mL}$ of distilled water and stirred well. $0.189 \mathrm{~g}$ of aniline was added into the mixture. After uniform stirring, silver nitrate solution was added. The mixture was stirred for $15 \mathrm{~min}$ and heated up to $90{ }^{\circ} \mathrm{C}$. After reaching $90{ }^{\circ} \mathrm{C}$, sodium hydroxide solution was added into the mixture and stirred further for one hour at room temperature. Thus, the silver nitrate had been reduced to a form of silver nanoparticles with average crystallite size less than $20 \mathrm{~nm}$. 


\subsection{Synthesis of silver dispersed copoly- mer}

$10 \mathrm{~mL}$ of silver colloidal solution was added to $70 \mathrm{~mL}$ of distilled water. $0.05 \mathrm{M}$ of m-toluidine and $0.05 \mathrm{M}$ of o-bromoaniline were dissolved in the solution mixture and stirred well. $10 \mathrm{~mL}$ of $1 \mathrm{M} \mathrm{HCl}$ solution was added. The temperature of the reaction was maintained between $0{ }^{\circ} \mathrm{C}$ to $5{ }^{\circ} \mathrm{C} .10 \mathrm{~mL}$ of $0.1 \mathrm{M}(2.28 \mathrm{~g})$ ammonium persulfate solution was added into the mixture and stirred for $24 \mathrm{~h}$. The obtained precipitate was washed with distilled water and acetone to remove the unreacted monomers and oligomers. Then all the samples were dried in a vacuum oven at $40{ }^{\circ} \mathrm{C}$ and subjected to various analytical characterizations.

\section{Instrumentation}

The UV-Vis spectra were recorded using ELICO SL-218 double beam spectrophotometer. FT-IR transmittance spectrum was recorded by SHIMADZU 8400S in the region of $400 \mathrm{~cm}^{-1}$ to $4000 \mathrm{~cm}^{-1}$ using $\mathrm{KBr}$ pellets. The surface morphology of the copolymer was analyzed by scanning electron microscopy (HR-SEM) HITACHISU 6600L instrument operating at $20 \mathrm{kV}$. X-ray diffraction pattern of the sample was recorded by Philips X'Pert Pro X-ray diffractometer with nickel filtered $\mathrm{CuK} \alpha$ radiation $(\lambda=1.5402 \AA)$ operating at $40 \mathrm{kV}$. The analysis was performed in the diffraction angle range $2 \theta$ of $10^{\circ}$ to $80^{\circ}$ at a rate of $10 \% \mathrm{~min}$. The samples were pelletized to a diameter of $13 \mathrm{~mm}$ using a vacuum press at $12 \mathrm{MPa}$. The DC electrical conductivity of the pelletized samples was studied using Keithley 6517 B electrometer. The PL study was performed using Shimadzu RF 8901 spectrofluorometer.

\section{Results and discussion}

\subsection{Solubility}

Solubility is an important parameter in industrial applications of polymeric materials. All the samples were dissolved in polar organic solvents, like DMSO, NMP, DMF and THF, where they were found to be highly soluble. The high solubility of copolymers may be due to the presence of side chain like methyl group and the bromine substituent may decrease the stiffness of the polymer backbone, thus leading to enhanced solubility of the polymer. Also the plasticizing nature of the solvent decreases the stiffness of the polymer leading to enhanced solubility [26]. The enhanced solubility can also be caused by presence of alkyl substitution in the 3-ring position which causes the steric crowding and makes the polymer backbone to twist from the regular planarity. Branched polymer shows more deformation and more amorphous state. Since the less crystalline polymer is loosely packed, hence the penetration of solvent is easy and causes better solubility.

The UV-Vis spectra were recorded using NMP as a solvent. Fig. 2a and Fig. $2 b$ depict the UV-Vis absorption spectra of the copolymer and silver dispersed copolymer composites, respectively. The absorption peaks are influenced by the functional groups attached to benzene rings. There are two main peaks showing the $\pi \rightarrow \pi^{*}$ transition and $\mathrm{n} \rightarrow \pi^{*}$ transition. In both figures, the increase in the co-monomer concentration causes the shifting of absorption peaks from higher wavelength to lower wavelength regions. It may be ascribed to the higher torsional angle between the adjacent phenyl rings. This is also due to higher steric repulsion between the methyl substituent and the hydrogen atom of the adjacent ring and it needs a higher energy for excitation [27]. The characteristic $\mathrm{n} \rightarrow \pi^{*}$ absorption band undergoes a red shift. When a polymer-metal nanocomposite is excited by a light energy, the photons are coupled at the interface and induce a charge density oscillation creating a strong absorption band at a particular wavelength. It is observed that dispersion of silver in the polymer matrix shows absorption band maximum shifted to the longer wavelength of $611 \mathrm{~nm}$ and it could be attributed to the spill-out of the s-electrons, which may increase the effective mass of the conduction electrons. This observation indicates the interaction of silver nanoparticles with nitrogen atoms in the polymer chain of the copolymer matrix by means of complex formation [28, 29]. 
Table 1. UV-Vis absorption.

\begin{tabular}{ccccccc}
\hline & \multicolumn{3}{c}{ Poly(m-tol-co-2-BrAn) copolymer } & \multicolumn{3}{c}{ Poly(m-tol-co-2-BrAn) copolymer } \\
& \multicolumn{3}{c}{ HCl } & \multicolumn{3}{c}{ Ag } \\
\hline Ratio/transition & $3: 1$ & $3: 2$ & $3: 3$ & $3: 1$ & $3: 2$ & $3: 3$ \\
\hline \hline & \multicolumn{5}{c}{ Wavelength $\lambda$ in nm } \\
\hline \multicolumn{1}{c}{$3: \pi^{*}$} & 323 & 317 & 313 & 320 & 317 & 314 \\
\hline $\mathrm{n} \rightarrow \pi^{*}$ & 600 & & 611 & \\
\hline
\end{tabular}

\subsection{FT-IR spectroscopy}

Fig. 3a and Fig. 3b present the FT-IR spectra of the copolymer and silver dispersed copolymer. FT-IR spectra show the characteristic peaks at $1585 \mathrm{~cm}^{-1}, 1490 \mathrm{~cm}^{-1}, 1272 \mathrm{~cm}^{-1}, 1153 \mathrm{~cm}^{-1}$, $1108 \mathrm{~cm}^{-1}, 890 \mathrm{~cm}^{-1}, 678 \mathrm{~cm}^{-1}$. The characteristic peaks around $1585 \mathrm{~cm}^{-1}$ and $1490 \mathrm{~cm}^{-1}$ are attributed to $\mathrm{C}=\mathrm{C}$ bond in quinoid and $\mathrm{C}=\mathrm{C}$ bond associated with the benzenoid ring, respectively. The peak at 1272 to $1288 \mathrm{~cm}^{-1}$ refers to the combination of $\mathrm{C}-\mathrm{N}$ stretching of the secondary aromatic amine. The peak around $1153 \mathrm{~cm}^{-1}$ indicates electron delocalization reaction to the conducting nature of the copolymer composites [30]. The strong intense peak around $1008 \mathrm{~cm}^{-1}$ to $1018 \mathrm{~cm}^{-1}$ in Fig. $3 \mathrm{~b}$ indicates the presence of $\mathrm{SO}_{3} \mathrm{H}^{-}$group and $\mathrm{CH}$ stretching in the benzenoid ring of DBSA moiety. The peak around $890 \mathrm{~cm}^{-1}$ denotes the $\mathrm{C}-\mathrm{H}$ out-of-plane deformation in the 1-4 distributed benzene ring. The peak at $810 \mathrm{~cm}^{-1}$ indicates the para-coupled phenyl ring resulting in the copolymer formation. The peak around $678 \mathrm{~cm}^{-1}$ to $669 \mathrm{~cm}^{-1}$ confirms the presence of $\mathrm{C}-\mathrm{Br}$ stretching in the copolymer. The band around $1105 \mathrm{~cm}^{-1}$ to $1111 \mathrm{~cm}^{-1}$ may be attributed to the aromatic $\mathrm{C}-\mathrm{H}$ in-plane deformation in the substituted benzene rings. The silver embedded copolymer shows the peaks of higher intensity than the $\mathrm{HCl}$ doped copolymer.

\subsection{XRD measurements}

Fig. 4a, Fig. 4b and Fig. 4c show XRD diffraction patterns of pure silver particles, poly(m-tol-co-2-BrAn) copolymer and silver dispersed poly(m-tol-co-2-BrAn) copolymer composites, respectively. Fig. 4a reveals the sharp characteristic peaks of pure silver particles. The characteristic peaks observed at $2 \theta=38^{\circ}, 44^{\circ}, 64^{\circ}$, $77^{\circ}$ are consistent with JCPDS Card No. 89-3722. Fig. 4b shows a typical amorphous peak around $2 \theta=24.5^{\circ}$. It is due to the periodicity parallel and perpendicular to the polymer chain $[31,32]$. It has been observed that the width of the peak gets narrowing as there is an increase in the comonomer content and it is attributed to the slight increase in the crystallization of the copolymer. Fig. $4 \mathrm{c}$ shows the sharp peaks in the pattern confirming that the copolymer composites are highly crystalline in nature. They confirm also dispersion of silver nanoparticles in the polymer matrix. The sharp peaks observed at $2 \theta=27.7^{\circ}, 32.2^{\circ}$, $46.2^{\circ}, 54.8^{\circ}$ and $57.4^{\circ}$ could be assigned to characteristic diffraction peaks for silver halide structure and it is consistent with the data in JCPDF Card No. 85-1335. The average crystallite size $D_{p}$ of the silver composite has been calculated using Scherrer formula:

$$
D_{p}=0.94 \lambda /\left(\beta_{1 / 2} \cos \theta\right)
$$

and it was found to be $15.6 \mathrm{~nm}$ [33]. Here, $\theta$ is the Bragg angle, $\beta$ is the full width at half maximum (FWHM) and $\lambda$ is the wavelength of X-ray used.

\subsection{Surface morphology}

The morphology of a polymer depends upon synthesis conditions of the material. Fig. 5a and Fig. $5 \mathrm{~b}$ show the scanning electron microscope images of poly(m-tol-co-2-BrAn) synthesized in presence of hydrochloric acid. The particles are well resolved and aggregate in regular spherical shapes. The particles range from $200 \mathrm{~nm}$ to $300 \mathrm{~nm}$ in size. This can be due to random orientation 


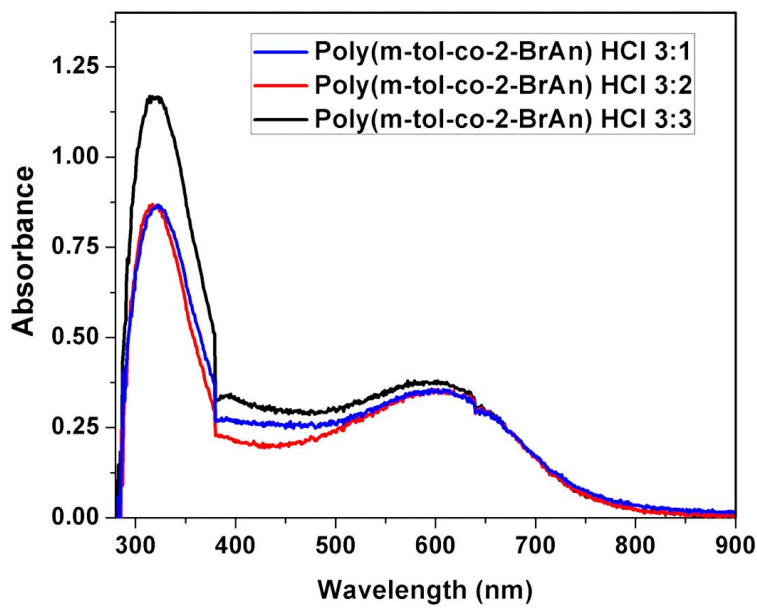

(a)

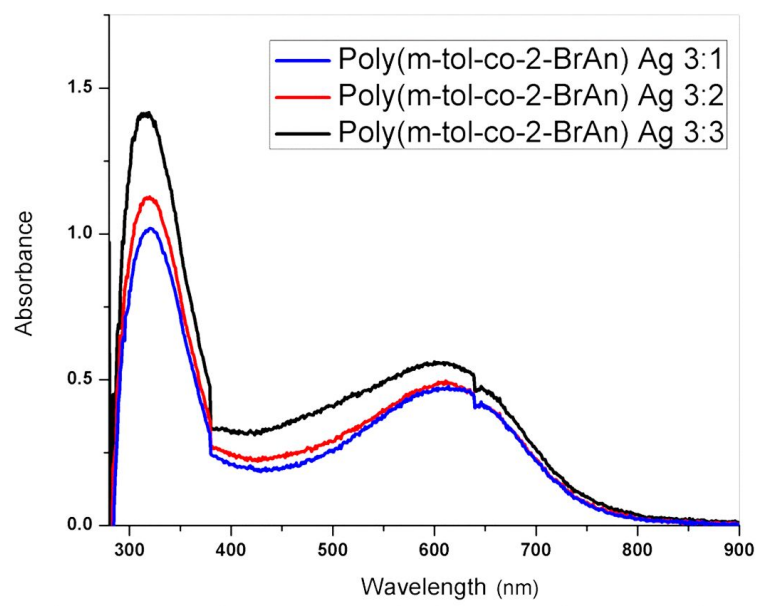

(b)

Fig. 2. (a) UV-Vis absorption spectra of copolymer; (b) UV-Vis absorption spectra of silver dispersed copolymer.

and copolymerization during the electrophilic substitution reaction with nitrogen. The formation of spherical particles is due to the entangled orientation of polymer chain resulting in coiled structure. A clear difference can be observed in the surface morphology of the pure copolymer and silver dispersed copolymer nanocomposites. Fig. 5c and Fig. 5d show the SEM images of silver embedded poly(m-tol-co-2-BrAn) copolymer. The surface morphologies of pure copolymer and silver dispersed copolymer are different. Bright spots of silver particles inside spherical particles, which do not exist in the pure copolymer, are seen.

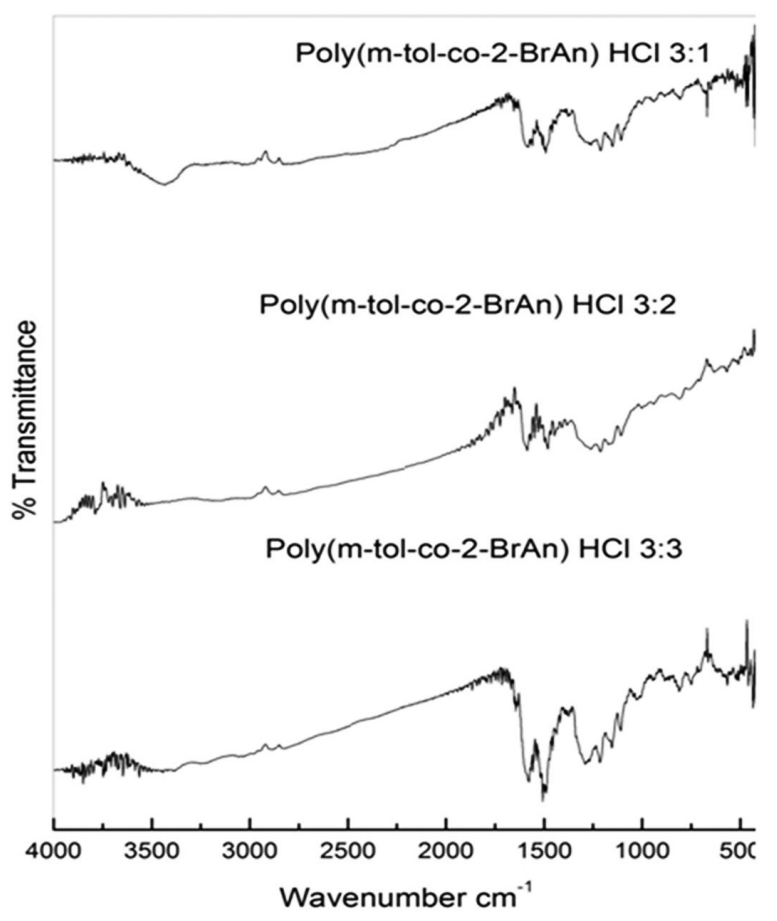

(a)

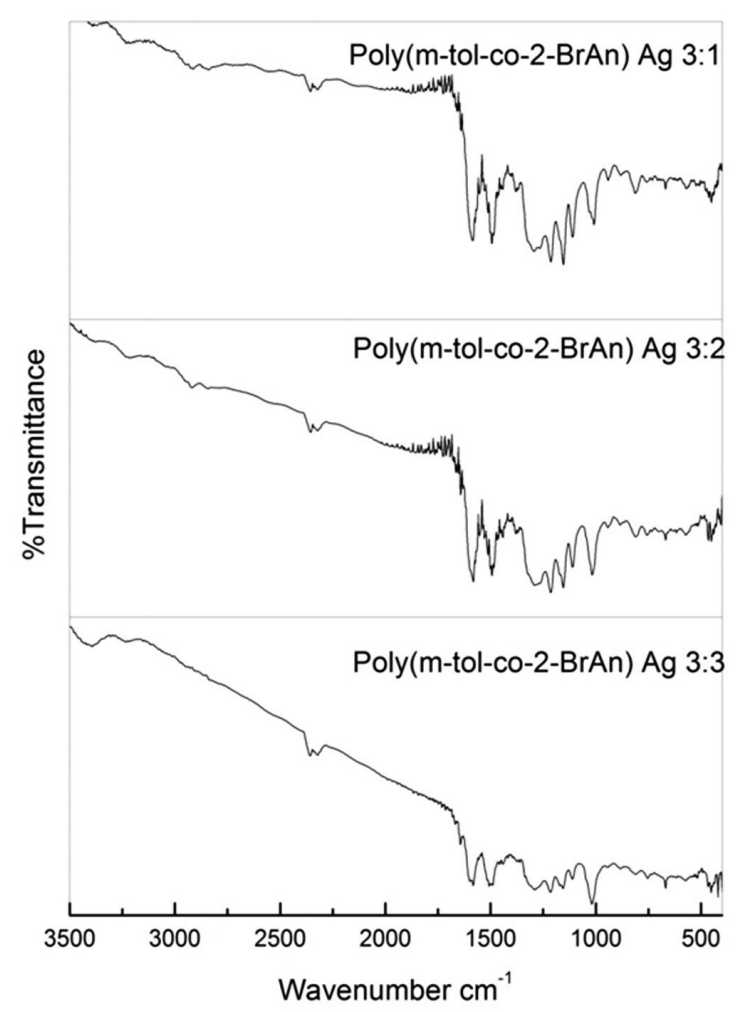

(b)

Fig. 3. (a) FT-IR spectra of copolymer, (b) FT-IR spectra of silver dispersed copolymer. 


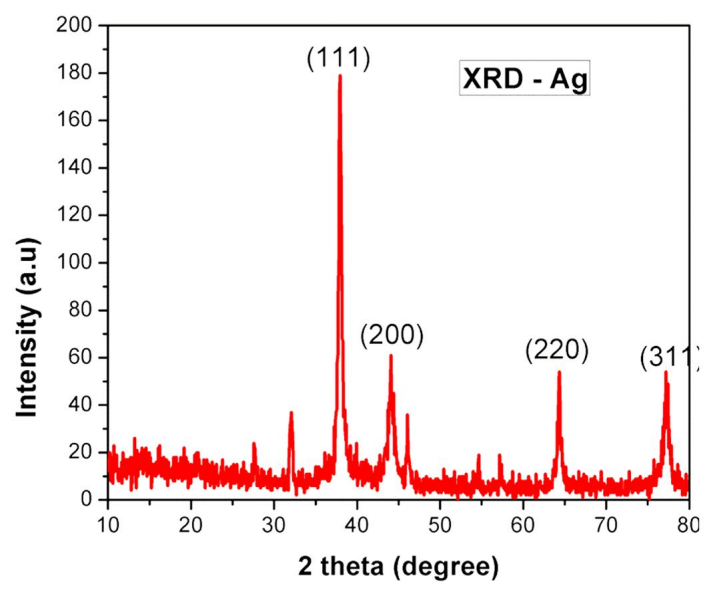

(a)

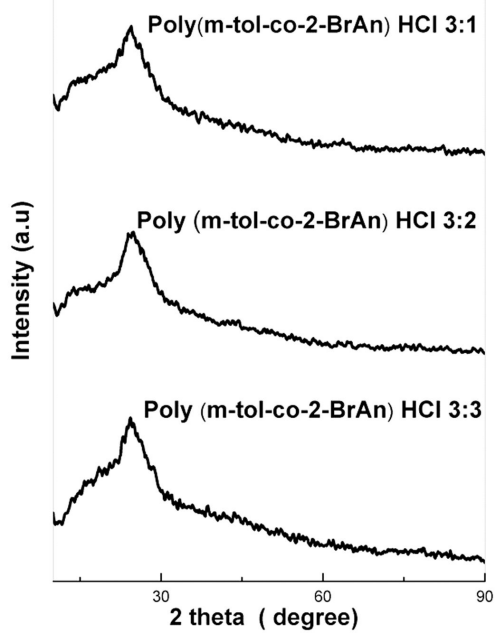

(b)

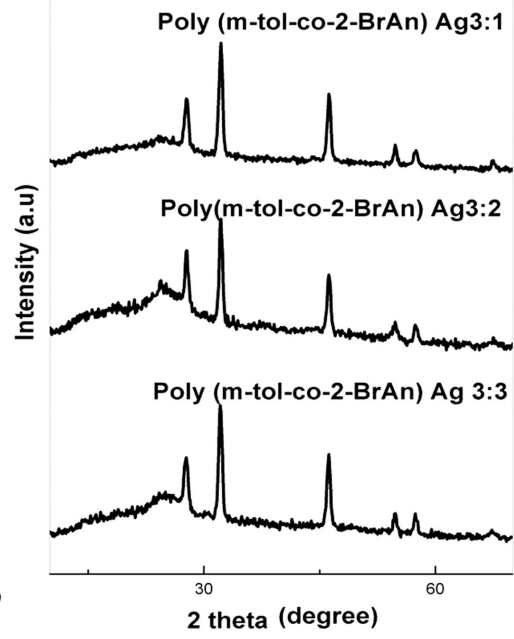

(c)

Fig. 4. (a) XRD pattern of silver nanoparticles; (b) XRD patterns of copolymers; (c) XRD patterns of silver dispersed copolymer.

Hence, this observation clearly confirms the uniform dispersion of silver nanoparticles without any kind metal particle aggregations. A large number of particles with the size ranging from $80 \mathrm{~nm}$ to $100 \mathrm{~nm}$ have agglomerated resulting in clustered morphology in the copolymer matrix. This was due to incorporation of metal ions into the copolymer chain which induced the aggregation state by forming a large number of small crystals resulting in nanosphere-like structures. There are porous void structures between the agglomerated particles and these particles are well connected to each other [34]. The agglomerated particles of well-defined structures resemble a cauliflower shaped morphological features with uniform particle size which are interconnected with each other. This networking morphology acts as conducting pathway of electrons between the particles.

\subsection{Photoluminescence spectroscopy}

Photoluminescence spectroscopy is a nondestructive technique to test the electronic structure of a material. Fig. 6 shows the photoluminescence spectra of the copolymer and silver dispersed copolymer. Photoluminescence was recorded 


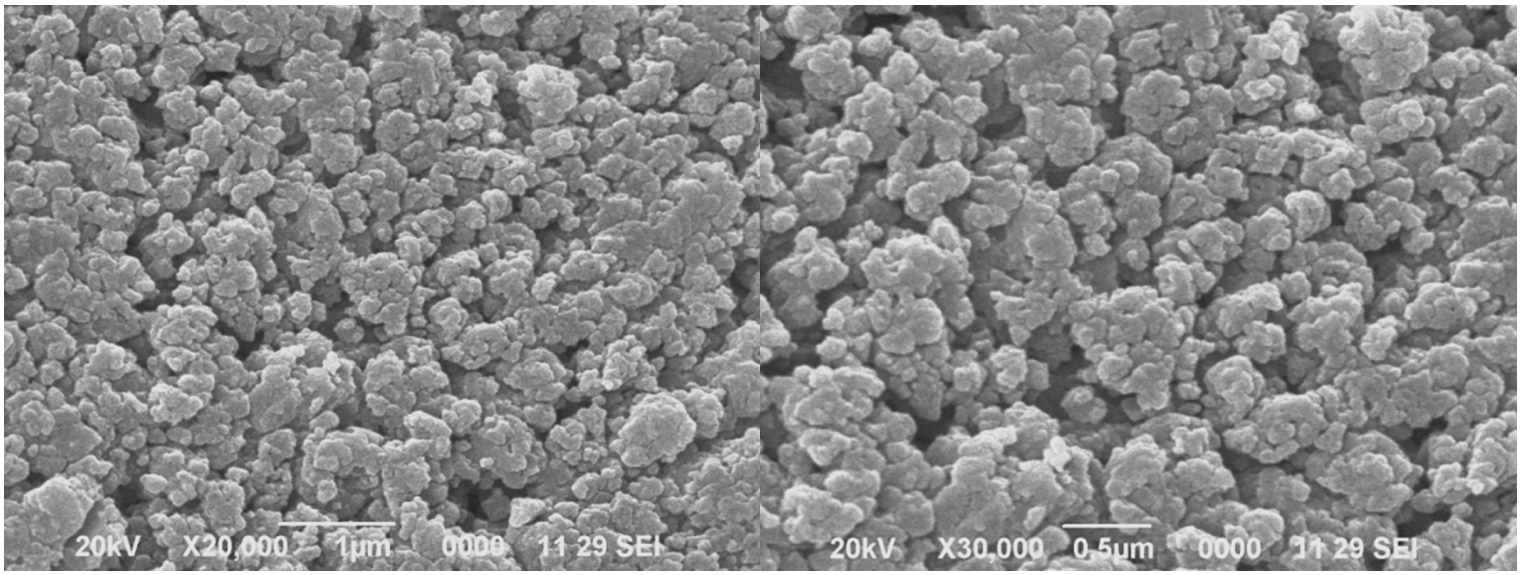

(a)

(b)

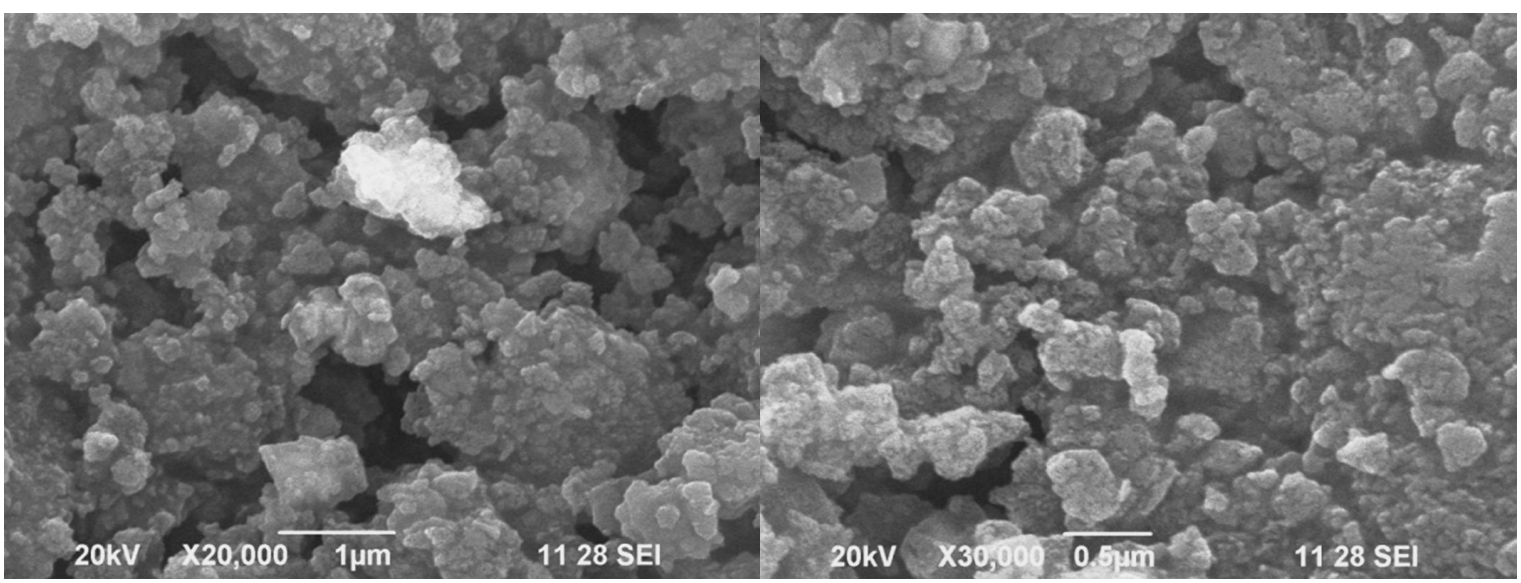

(c)

(d)

Fig. 5. (a) and (b) SEM images of poly(m-tol-co-2-BrAn) HCl 3:3; (c) and (d) SEM images of poly(m-tol-co-2BrAn) Ag 3:3.

at an excitation wavelength of $320 \mathrm{~nm}$. There are two peaks around $417 \mathrm{~nm}$ and a little sharp peak at $642 \mathrm{~nm}$ in the spectra. The peak evidences the presence of photo-excited electrons in the copolymer chain. The silver dispersed copolymer shows reduction of the PL spectra intensity. The reason for the reduction can be the charge transfer of excited electrons from the copolymer to the silver particles [35].

\subsection{Conductivity}

Table 2 gives the DC electrical conductivity values of the copolymers measured at room temperature. The electrical conductivity of the copolymer was found to be varying from $2.3 \times 10^{-6}$ to $3.38 \times 10^{-3} \mathrm{~S} / \mathrm{cm}$. The electrical conductivity of the silver embedded copolymer has a lower value than the pure copolymer and this may be due to the presence of silver particles that can increase the steric hindrance, multiple reflections and may reduce the electron transfer. The electrical conductivity values for 3:2 ratio of m-toluidine and o-bromoaniline copolymers (with and without $\mathrm{Ag}$ ) is high when compared to the other ratios. In the case of complex formation, the electrons are usually transferred by the free protonated molecule but the decreased conductivity may be due to charge reflection that takes place between the silver particles and the polymer molecules [36]. Obviously, 


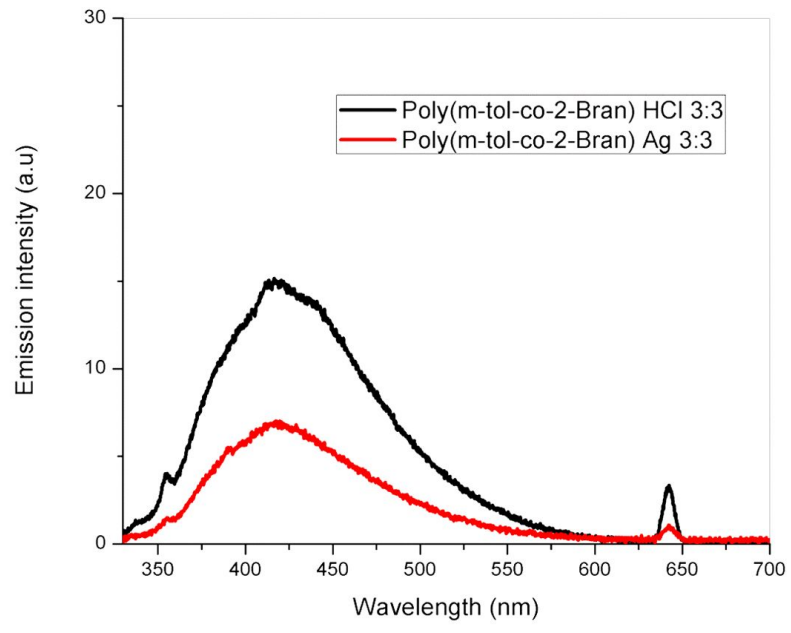

Fig. 6. Photoluminescence spectra of the copolymer and silver dispersed copolymer.

the silver containing nanocomposite should show higher conductivity than the pure copolymer. These contrasting results may be due to higher concentration of the co-monomer and its interaction with the silver halide structure that decreases the electron charge transport in the polymer backbone.

Table 2. Electrical conductivity values.

\begin{tabular}{ccc}
\hline S. No. & Copolymer ratio & $\begin{array}{c}\text { Conductivity } \\
{[\mathrm{S} / \mathrm{cm}]}\end{array}$ \\
\hline \hline 1. & Poly(m-tol-co-2-Bran) 3:1 & $2.34 \times 10^{-6}$ \\
2. & Poly(m-tol-co-2-Bran) 3:2 & $3.38 \times 10^{-3}$ \\
3. & Poly(m-tol-co-2-Bran) 3:3 & $4.4 \times 10^{-4}$ \\
4. & Poly(m-tol-co-2-Bran) 3:1 Ag & $2.24 \times 10^{-5}$ \\
5. & Poly(m-tol-co-2-Bran) 3:2 Ag & $1.32 \times 10^{-4}$ \\
6. & Poly(m-tol-co-2-Bran) 3:3 Ag & $3.87 \times 10^{-6}$ \\
\hline
\end{tabular}

\section{Conclusions}

A new series of poly(m-toluidine-co-2bromoaniline) copolymers and silver embedded poly(m-toluidine-co-2-bromoaniline) copolymers have been synthesized successfully with different molar ratios of co-monomer and characterized by various analytical techniques. The copolymer composite was found to be highly soluble in the common polar organic solvents. The absorption spectra show the red shift of the electronic transition when silver nanoparticles are embedded into the copolymer matrix. In contrast, an increase in the co-monomer concentration causes that the absorption peak is slightly blue shifted. FT-IR study confirms the formation of the copolymer with the characteristic stretching frequencies. The XRD study confirms the presence of broad peak of the amorphous copolymer and sharp peaks confirm the presence of silver particles. The room temperature electrical conductivity values were found to be of the order of $10^{-3} \mathrm{~S} / \mathrm{cm}$ to $10^{-6} \mathrm{~S} / \mathrm{cm}$. Since the silver embedded copolymer causes a reduction in the photoemission intensity, these composites were found to have good potential applications in the field of optoelectronics.

\section{Acknowledgements}

The authors are thankful for the Council of Scientific and Industrial Research (CSIR), Government of India, for funding (Grant No. 01/2514/11/EMR-II). The authors are also thankful for the Management of Bannari Amman Institute of Technology for providing necessary laboratory facility to carry out the research work.

\section{References}

[1] Nalwa H.S., Handbook of Conducting Polymers, Wiley, New York, 1986.

[2] Finch C.M., Ssrichantaropas S., Mailey S.W., GraCE I.M., GARCIA-SUAREZ V.M., LAMBERT C.J., J. Phys-Condens. Mat., 20 (2008), 22203.

[3] Guenza M.G., J Phys-Condens. Mat., 20 (2008), 33101.

[4] Kumar D., Synth. Met., 114(2000), 369.

[5] Mahudeswaran A., Manoharan D., ChanDRASEKARAN J., VIVEKANANDAN J., ViJAYANAND P.S., Mater. Res., 18 (2015), 482.

[6] Mahudeswaran A., Vivekanandan J., VIJAYANANDAN P.S., Asian J. Chem., 27 (2015), 4501.

[7] Nair J.R., Destro M., Bella F., Appetecchi G.B., Gerbaldi C., J. Power Sources, 306 (2016), 258.

[8] Chuanyu S., Yu W., Mater. Sci.-Poland, 32 (2014), 521.

[9] Chuanyu S., Yu W., Mater. Sci.-Poland, 33 (2015), 193.

[10] Dobroczynska J.I., Grabas K., Mater. Sci.-Poland, 31(2013), 95.

[11] Bella F., Griffini G., Correa-Baena J., SARACCO G., Gratzel M., Hagfeld A., Turri S., Gerbaldi G., Science, 354 (2016), 203.

[12] Pintossi D., Iannaccone G., Colombo A., Bella F, Valimaki M., Vaisanen K., Jast J., Levi M., Gerbaldi C., DragonetTi G., TurRi S., GRIFFINI G., Adv. Electron. Mater., 2 (2016), 1600288. 
[13] Berardi S., Francas L., Neudeck S., Maji S., Buchholz J.B., Meyer F., Llobet A., Chem. Sus. Chem., 8 (2015), 3088.

[14] Wang L., Lu X., Lei S., Song Y., J. Mater Chem., 2 (2014), 4491.

[15] Ma Y., Li N., Yang C., Yang X., Colloid Surfaces A, 269 (2005), 1

[16] Santos R.F.S., Andrade C.A.S., Dos Santos C.G., Melo De C.P., J. Nanopart. Res., 15 (2013), 1408.

[17] Mullane A.P.O., Dale S.E., Day T.M, Wilson N., MacPherson J.V., Unwin P.R., J Solid State Electr., 10 (2006), 792.

[18] Bhaiswar J.B., Salunkhe M.Y., Dongre S.P., Int. J. Sci. Res. Publ., 3 (2013), 1.

[19] Gupta K., Jana P.C., MeikaP A.K., Synth. Met., 160 (2010), 1566.

[20] Biswas S., Dutta B., Bhattacharya S., Appl. Surf. Sci., 292 (2014), 420.

[21] Bober P., Trachova M., Prokes J, Varga M, STEJSKAL J., Electrochim. Acta, 56 (2011), 3580.

[22] Correa C.M., Faez R., Bizeto M.A., Camilo F.F., RSC Adv., 2 (2012), 3088.

[23] Bober P., Sejskal J, Trechova M., HromadKova J., Prokes J., React. Funct. Polym., 70 (2010), 656.

[24] Vivekanandan J., Mahudeswaran A., Jeeva A., ViJayAnand P.S., J. Polym. Mater., 31 (2014), 463.
[25] Vivekanandan J., Mahudeswaran A., Tang X.Y., Kumbar S.G, Vijayanand P.S., J. Polym. Mater., 69 (2015), 964.

[26] Vijayanand P.S., Mahudeswaran A., Vivekanandan J., Kumbar S.G., Tenside. Surfact. Det., 52 (2015), 230.

[27] Sharma S., Kumar D., Indian J. Eng. Mater. S., 17 (2010), 231.

[28] Choudhury A., Sensor Actuat. B-Chem., 138 (2009), 318.

[29] Cochet M., Louran G., Quillard S., Buisson J.P., Lefrant S., J. Raman Spectrosc., 31 (2000), 1041.

[30] Zhang Y.X., Wang Z., Ye W, Qian H., Lin Z., Colloid. Polym. Sci., 291 (2013), 2903.

[31] Yan F., Xue G., J. Mater. Chem., 9 (1999), 3035.

[32] YAng J., Yin H., Macromol. Mater. Eng., 297 (2012), 203.

[33] Xu X., Pan Q., Shun Y., Tian Z., Sensor. Actuat. BChem., 66 (2000), 277.

[34] Stejskal J., Sapurina I., Trchova M., Prog. Polym. Sci., 35 (2010), 1420.

[35] Zhang X., Tang B., Kong F., Yang H., Lin B., Solid State Sci., 21 (2013), 106.

[36] Weiber E.A., Jannasch P., J. Membrane Sci., 520 (2016), 425.

Received 2016-10-19 Accepted 2019-04-23 